\title{
Construcción de un Modelo de Trabajo de Gestión Documental en la Organización, en el Contexto de la Actividad Archivística
}

Sergio Escobedo Guerrero

Bibliotecario Documentalista

Especialización en Archivística

Universidad José Santos Ossa Chile-Antofagasta

\section{Resumen}

El artículo propone y desarrolla el principio de gestión documental para la planificación archivística dentro de la organización, dicha gestión debe comenzar en el primer nivel de acción que es la Dirección del Archivo sustentando el valor de la información documental para el trabajo de las personas dentro de la organización, el valor patrimonial que ella representa en la construcción e historia de la institución y el reconocimiento como un talento para el aprendizaje.

A partir de la incorporación de la gestión documental se desarrollan las siguientes áreas de acción: Primero el enfoque del análisis de procesos, la descripción, caracterización y reconocimiento de los procesos al interior de la organización como fuentes de generación documental. Segundo el análisis documental, para lo cual se debe tener la más amplia competencia en el manejo de generación documental esto quiere decir, analizar en que fases de los procesos de trabajo se produce documentación y los soportes o medios donde estas se registran. Tercero la selección y valoración documental en los lugares donde se genera y se dispone la documentación (archivos de gestión o de oficina), efectuando para este caso una preselección y prevaloración documenta. Cuarto desarrollo de mecanismos de control, para verificar cómo se está produciendo la documentación y cómo debe fluir, sin interferencias, desvíos o retrasos hacia el archivo o los lugares destinados para ello.

\section{Introducción}

En materia archivística, el quehacer disciplinario y la experiencia profesional van delineando los vínculos que existen entre la documentación y las actividades que realizan las instituciones, ya sea en forma individual o en el contexto del trabajo organizado. El concepto de "valor documental" es un elemento esencial en torno al cual se desarrolla la actividad archivística y donde los documentos están sujetos a un ciclo de vida determinado. A este respecto podemos distinguir dos clases de valor documental: a) el valor primario, que representa el valor informativo concreto e inmediato de todo documento que se genera como producto de un proceso, actividad o circuito de trabajo, y que generalmente es el resultado del inicio y término de un asunto respondiendo a aspectos operacionales, prácticos, sirviendo muchas veces como elemento de prueba y verificación; b) el valor secundario, que es el valor de conservación y preservación del documento en el transcurso de su vida y que está encaminado a su utilización como antecedente e información de investigación.

La documentación ha sido desde siempre el producto que refleja el quehacer de las instituciones; es ahí donde gira tanto la teoría como la práctica de la actividad archivística. Pero otras técnicas florecientes han hecho su arribo al alero de esta disciplina. Es el caso de la Gestión Documental, al respecto (Lodolini1993) señala que "durante la década del 50 comenzaron las primeras acciones de carácter práctico y luego se desarrolló en la literatura norteamericana el concepto de Record Management". A1 término de la Segunda Guerra Mundial, esta metodología fue empleada para organizar la información documental acumulada por el Estado; posteriormente dio el impulso para mejorar los aspectos administrativos en la generación de la documentación publica en 
los Estados Unidos. (Ruiz Rodríguez1995) explica que "la Gestión Documental comprende el ciclo de vida completo de la documentación, desde su producción hasta la eliminación final o su envío al archivo para su conservación permanente evitando lo innecesario."

Para comenzar nuestro trabajo sobre Gestión Documental es necesario determinar en primer lugar qué es lo que constituye un archivo. Especialistas en el tema, como Elio Lodolini, Antonio Heredia y Manuel Romero Tallafigo, plantean como elemento sustantivo que el recurso documental, así como el soporte que contiene la información son la materia principal para el tratamiento archivístico. Según este punto de vista, una definición adecuada sería la de (Ramos Jimenez1999) "el archivo deberá reunir el conjunto de documentación, sea cual fuere su fecha, su forma y el soporte material, que es producido, recibido por cualquier persona física o moral o por cualquier organismo público o privado en el ejercicio de su actividad o conservada por su creador o sucesor para su propia necesidad tramitado y dispuestos en un archivo." Además, podríamos agregar la disponibilidad para su uso en el transcurso de su ciclo de vida.

Otro elemento importante que debe estar presente a la hora de entender el proceso de generación o producción documental en el contexto organizacional, que siempre hay un producto o acción con un propósito definido donde la documentación es un testimonio de lo que un proceso de trabajo debe alcanzar. Por ejemplo el objetivo de una empresa dedicada a la venta de aditivos para alimentos cárneos no es mantener expedientes detallados de sus clientes, sino diseñar la mejor estrategia de venta para aumentar su cartera de clientes y captar la opción de compra de potenciales clientes; el papel de la documentación es dar soporte a la actividad, generando un subproducto que apoye el curso de las acciones comerciales de la empresa. En términos globales podemos afirmar que la documentación comienza a estructurarse en la medida que las actividades de la organización se van desarrollando de manera sistemática. Es necesario recalcar que la Gestión Documental no sólo esta llamada a intervenir la documentación, sino a actuar al interior de la organización en los ciclos documentales.

Tenemos entonces que el trabajo de Gestión Documental es la acción que comienza a realizarse en el nivel primario de la generación documental, entendiendo esta acción como la relación que se debe producir en las áreas y actividades de trabajo de la organización, que comprometa de alguna forma la generación de documentos y la participación sistemática del profesional archivero.

\section{Problemas a la hora de enfrentar la Gestión Documental en el contexto archivístico}

El aumento de la masa documental producida por la administración pública es uno de los problemas que enfrentan los archiveros en los países con tradición archivística como por ejemplo España, Francia o Italia. Tal situación es fruto de un variado tratamiento de asuntos así como la complejidad en los trámites para dar respuesta a las necesidades de los ciudadanos, haciendo que el Estado intervenga cada vez más en los asuntos de las personas. Por ejemplo, como lo ilustra (Akotia1994) en el gobierno de Ghana "la máquina del gobierno rodeada de burocracia y política ha creado grandes volúmenes de documentación por razones de necesidades administrativas; el Archivo Nacional no puede absorber la acumulación de documentación inactiva que combinada con la 
documentación en curso, crea problemas en el almacenamiento de los documentos en los tribunales."

Pero el tema es aún más complejo. Se observa un aumento desmesurado de la documentación en organizaciones que sí disponen de sistemas de archivo debido a diferentes factores, entre los que se menciona la burocracia, circuitos de trabajo mal diseñados, procedimientos inadecuados que en vez de crear una acción más directa producen gran cantidad de información muchas veces innecesaria, inútil y repetitiva con escaso valor primario, que impide a la organización disponer de antecedentes para una adecuada retroalimentación. Por si todo lo anterior fuera poco, se observa también un escaso uso de la documentación dentro de las propias instituciones.

Dentro de la empresa privada el problema no es menor, ya que el manejo y tratamiento de la información documental versus la aplicación de la tecnología de información (TI), sigue quedando en manos de los informáticos no entregando una respuesta eficiente a los directivos, ejecutivos o empleados, como lo señala (Drucker1999) "la información constituye al interior de la empresa el recurso más importante pero con frecuencia se deja estas decisiones a los administradores de TI, y donde los ejecutivos o profesionales se preguntan ¿cuál es la información que necesitan las personas con las que trabajo y de los directivos de quien dependo?, ¿cómo debo tener dicha información y en que plazos?, ¿qué información necesito para desarrollar mi trabajo?." Aún la información en la empresa es un problema no resuelto; no se puede responder a lo anterior sin antes tratar de responder también otras preguntas, como por ejemplo: ¿los procesos y circuitos de trabajo están debidamente diseñados y qué información emana de ellos?, ¿la documentación (información) generada por una actividad en una unidad de trabajo o departamento es un producto permanente o esporádico?, ¿la unidad de trabajo o departamento ha definido las tipologías documentales que caracterizan y consolidan sus procesos de trabajo?, ¿qué estructura de forma y fondo debe tener la información para dar respuesta al valor primario, que sin duda es el elemento principal a la hora de resolver un problema o tomar una decisión?

En definitiva, el problema no sólo está en la documentación sino en definir cómo se genera y de dónde emana. Habría que hacer un rediseño de los métodos y circuitos de trabajo y establecer procedimientos más sencillos; todo esto bajo una metodología de normalización, racionalidad y economía de recursos.

Desgraciadamente en algunos "seudoarchivos" se hace imposible revertir la situación, estos están pensados como unidades para almacenar y disponer la documentación en estanterías, con una total falta de metodología propia de la disciplina archivística para el tratamiento documental. La carencia de una asesoría adecuada representada por un profesional archivero limita su desarrollo como unidad importante en el quehacer de la organización, acumulando gran cantidad de documentación en espera de ser derivada a otro depósito o expurgados para dar paso a nuevas cajas de archivos.

La eliminación indiscriminada de la documentación por falta de espacio en las mismas unidades de trabajo o en bodegas habilitadas artesanalmente para su acumulación es otro aspecto problemático; se trata de una práctica frecuente incluso en instituciones que creen manejar apropiadamente la documentación en sus archivos, eliminando documentos sin conocer las variables que deben adoptarse en este procedimiento. 
La llagada de los soportes magnéticos ha puesto en el tapete la necesidad de establecer procedimientos para recibir o custodiar información con características distintas al papel. Muchas veces el profesional archivero no dispone de pautas claras para manejar este tipo de recursos; otras veces se asume que este tipo de información no forma parte de un archivo y se deja en manos de los "informáticos" que se limitan con frecuencia a adquirir soportes de respaldo más poderosos para su almacenamiento.

\section{Integración archivística y gestión documental en la organización}

Para delinear una teoría y práctica archivística más innovadora se debe abordar el manejo y tratamiento de la información documental con una metodología archivística moderna armonizada con la técnica de Gestión Documental. Así se propuso en el Congreso de Quebec en 1992, donde se planteó la idea de desarrollar la disciplina como archivística integrada para poder intervenir en todo el ciclo de vida de los documentos y su entorno. Esto significa unir en una misma metodología las técnicas tradicionales del tratamiento archivístico documental con una gestión adecuado en el nivel primario.

Con respecto a lo señalado en el párrafo anterior citaremos algunos planteamientos en el tema. (Mnjama1996), por ejemplo, afirma que de esta forma es posible "lograr una economía en la generación de la información documental, su uso, su conservación y la disposición de los documentos". Por otra parte, Lennon identifica la Gestión Documental dentro de la administración organizacional como el ciclo de vida de la información desde su creación, recuperación, transferencia y conservación permanente. Una definición un poco más cercana al marco de análisis es la de Peter Emmerson que define la Gestión Documental como "un sistema de administración por el cual se establece para la documentación de la organización un control en su creación, distribución, disposición en el archivo, recuperación y almacenamiento en el curso de su negocio."

Es deseable lograr que se produzca una evolución hacia lo que los norteamericanos llaman Record Management, que pone énfasis en la vinculación con las actividades de la organización, y donde tenga una alta prioridad el valor primario, es decir, la utilidad de la documentación para la acción en el quehacer organizacional.

A mi juicio la Gestión Documental entendida en los términos recién expuestos, se debe establecer como una relación entre la organización y el valor que representa la documentación al interior de ella, como factor de aprendizaje y conocimiento. Para desarrollar esta actividad con propiedad es indispensable que quede en manos de un profesional con capacidad en el manejo documental (Archivero) y que además intervenga en la organización, principalmente en los puntos de trabajo de los empleados. 


\section{Principio de posicionamiento de gestión global del sistema de archivo como estrategia de interrelación dentro de la organización}

Hay un principio que es necesario establecer para concebir con propiedad un sistema de archivo: el posicionamiento de gestión documental global, que se debe propiciar en el primer nivel de acción representado en la Dirección del Archivo. Este principio debe estar sustentado, en primer lugar por el valor que tiene la información documental para el trabajo de las personas dentro de la organización; en segundo lugar el sustento patrimonial que ella representa en la construcción e historia de la organización, y tercero el reconocimiento en la información documental como un talento para el aprendizaje. Visto así, el archivo no puede ser concebido como una figura más dentro de la estructura organizacional, o como una unidad aislada de depósito de documentos.

En el contexto global el sistema de archivo es la consolidación y el propio reflejo de la organización (unidades de trabajo, secciones, departamentos, procesos, cadenas de mando y personas), es decir, el archivo es la institución que crece en plenitud.

La adopción de este principio permite que el profesional archivo pueda desarrollarse y a la vez mejorar sus métodos de trabajo, conociendo y relacionando mejor el quehacer de la organización y su producción documental. Se podría dar el caso por ejemplo, de un desastre (incendio, inundación) y con ello la destrucción la documentación considerada vital para una organización, lo que provocaría a la hora de reconstrucción de los procesos de trabajo y tareas administrativas un lógico retraso en la continuidad de sus actividades. Pero el profesional archivero al prever la existencia de documentación de características especiales, propondría a la organización la implementación de un programa que permitiera salvaguardar este tipo de documentos y entonces a la empresa no le tomaría mucho tiempo reconstruir y normalizar su funcionamiento. Otro ejemplo de aplicación de Gestión Documental y que puede abordar el profesional archivero, al detectar una excesiva burocracia en el uso y llenado de formularios para determinado trámite, pueda proponer un nuevo diseño de tipología documental estructurado para simplificar su gestión y así agilizar las acciones administrativas.

\section{Acciones de trabajo de gestión documental de línea en la organización}

Como hemos demostrado anteriormente, la Gestión Documental comprende algo más que una readecuación y renovación de técnicas archivísticas del profesional archivero. Las habilidades y conocimientos que debe desarrollar este profesional se pueden resumir en cuatro áreas de acción. La primera está enfocada al análisis de procesos, es decir, a la descripción, caracterización y reconocimiento de los procesos al interior de la organización como fuentes de generación documental. Una segunda área lo constituye el análisis de información documental, para lo cual debe tener una amplia competencia en el manejo de generación documental, analizando en que fases de los procesos de trabajo se producen documentos y los soportes o medios donde estos se registran. Una tercera área comprende la selección y valoración documental en los lugares donde se genera y se dispone (archivos de gestión o de oficina), efectuando una preselección y prevaloración de la misma. Finalmente, una cuarta área abocada al desarrollo de mecanismos de control, para verificar cómo se está produciendo la documentación y 
cómo debe fluir sin interferencias, desvíos o retrasos hacia el archivo o los lugares destinados para un depósito parcial o permanente.

Cada una de estas áreas y los elementos que las componen deben ser mirados como una unidad global pero, a la vez, individual. Su aplicación no está determinada por un orden específico, sino que los pasos deben ejecutarse según las características del sistema de archivo en la organización.

Al proyectar la creación de un sistema de archivo es conveniente desarrollar previamente un buen trabajo de Gestión Documental; esto implica comenzar a analizar dentro de plazos prudentes la documentación en una fase primaria al interior de la organización. Resulta más costoso tomar la decisión de implementar directamente un archivo sin antes hacer un estudio del estado de la documentación institucional o al menos, haber realizado un catastro de los recursos documentales y la proyección de crecimiento.

En el esquema adjunto se Esquema de niveles de gestión en la estructura organizacional de un sistema de archivo

puede identificar la estructura que compone la Dirección y bajo dicha dirección la Gestión Directiva, con las acciones que fundamentan la estrategia global de desarrollo del sistema de archivo; y junto a ella podemos ver también la Gestión Documental de Línea, que es el nivel de gestión donde debe

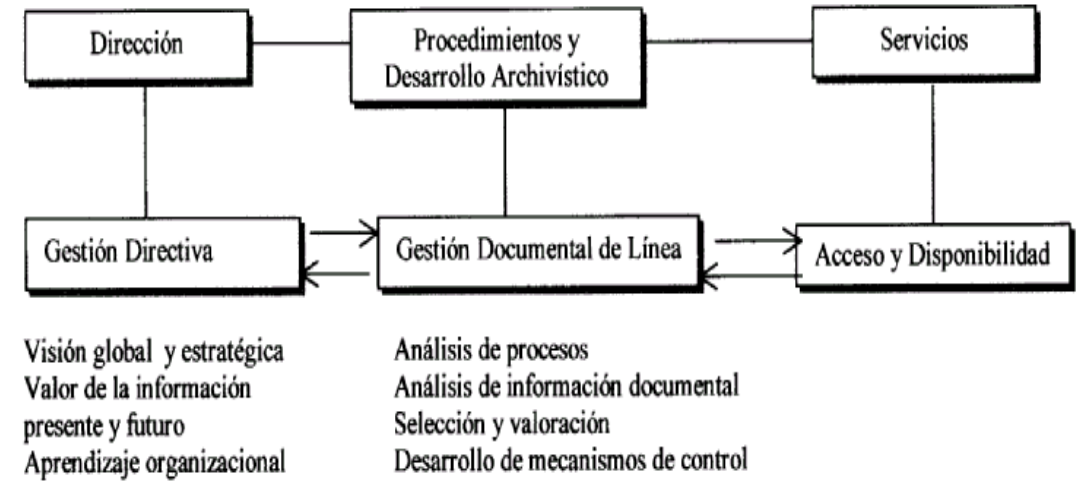
intervenir el profesional archivero, ejecutando las actividades de Gestión Documental, retroalimentando al sistema de archivo para proponer los cambios y las mejoras contribuyendo al desarrollo armónico entre el quehacer organizacional, los procesos de trabajo y la producción documental, consolidando un sistema de archivo moderno y con capacidad de influir en la organización.

\section{1 - Análisis de procesos al interior de la organización}

Como herramienta para la verificación y seguimiento de la producción documental, la archivística ha incorporado recientemente el concepto de procesos muy usado en el área de la ingeniería y administración. Permite visualizar las etapas, pasos o fases de trabajo encadenadas y relacionadas que se van produciendo para lograr el objetivo esperado. Si a esto le agregamos el recurso de información documental que deriva de él, podemos afirmar que se trata de una herramienta efectiva para conocer cómo se genera la información en un proceso. Los procesos como matriz, ayudan al profesional archivero a entender cómo se tramitan y realizan los asuntos en una organización, las funciones que al interior de la misma generan información en forma sistemática, los departamentos que consultan periódicamente la información. Además, es una 
herramienta importante que la archivística utiliza para organizar la documentación y aplicar mejor el principio de procedencia y respeto al orden natural de los documentos. Al respecto (Lorino1996) explica que "se llamará proceso al conjunto de actividades destinadas a la consecución de un objetivo global tanto material como inmaterial, por tanto los procesos son combinaciones de distintos modos de proceder, que permiten obtener un resultado material o inmaterial preciso."

Si bien Lorino relaciona un conjunto de actividades orientadas hacia un objetivo común con el concepto de proceso, también es válido decir que todo grupo de tareas, circuitos de trabajo, pasos simultáneos, que permitan cumplir un objetivo se puede asociar igualmente al concepto de proceso.

Los procesos se caracterizan por ser transversales, jerárquicos y en las grandes divisiones, funcionales (recursos humanos, marketing, producción, administración, etc.). Cada proceso tiene una salida global única y tiene un cliente interno o externo del cual deriva natural o sistemáticamente un recurso de información documental, que se expresa en un contexto y un soporte propio a su naturaleza para su lectura y compresión.

\section{A ) Características de los procesos}

Entre las principales características de los procesos podemos mencionar las siguientes:

Sencillez: Esta característica es necesaria para que sean fáciles de manejar y modificar; generalmente los procesos contemplan un pequeño número de objetivos y de indicadores de control para cada actividad.

Claridad: Un proceso adecuado debe estar constituido por indicadores concretos, perfecta y fácilmente comprensibles por el personal involucrado en ellos.

Evolución: Debe estar concebido de manera que pueda adaptarse a eventuales cambios de circunstancia y de estrategias.

Integración: Deben estar tan integrados como sea posible: deben presentar una unidad en sus pasos y una relación efectiva con otros proceso cuando estos se entrecruzan.

\section{B ) Cómo reconocer una actividad de proceso en el contexto del desarrollo organizacional}

Para reconocer un proceso en el contexto del desarrollo organizacional, deben cumplirse las siguientes condiciones:

Que la actividad sea realizada por una persona o un equipo.

Que emplee un conjunto homogéneo de conocimiento.

Que tengan un comportamiento coherente desde el punto de vista de los costos y de la eficiencia.

Que pueden caracterizarse globalmente por entradas y salidas bien definidas. 
Que tenga una importancia significativa para la eficiencia económica de la organización.

Que los conocimientos movilizados constituyan un conjunto lógico que define una competencia global individual o colectiva.

$>$ Que las actividades sean dinámicas, es decir, que puedan sufrir cambios, finalizar, modificarse, refundirse, etc.

Que se trate de actividades de carácter genérico, como por ejemplo, función personal, función de finanzas, función de producción, función de relaciones publicas, etc.

\section{2 - Análisis de información documental}

Esta fase de la Gestión Documental comprende principalmente la identificación de la producción documental, así como el reconocimiento de las distintas tipologías documentales implantadas en la organización. En esta labor, el profesional archivero de línea deberá tener la capacidad de identificar, analizar y entender las distintas tipologías documentales y sus contenidos, proponer soluciones creativas para enfrentar posibles necesidades que deriven del análisis de procesos de trabajo. También debe estar en condiciones de entregar soluciones reales a necesidades de la organización, por ejemplo, lograr una mayor eficiencia y efectividad en las acciones de comunicación en los distintos departamentos; para ello puede revisar los dispositivos de comunicación y sus flujos internos.

La implementación y la mantención de un archivo institucional es una actividad que inicialmente es compleja y en el transcurso del tiempo puede presentar algunos problemas, ya que la vida de la documentación que acompaña el desarrollo de la organización no se mantiene imperturbable. Por lo general, el profesional archivero debe realizar toda una etapa de reconstitución de las series documentales y de una selección y valoración de los documentos que constituye el fondo del archivo. Además debe enfrentar el ingreso de nuevos documentos, carga de trabajo que no le permite hacer un recorrido regular por los departamentos o áreas de trabajo, con el objeto de verificar los archivos de oficinas, y otros aspectos relacionados con la producción documentación; disponer del tiempo necesario ayudaría a crear un vinculo más estrecho entre la organización y el archivo. Este vínculo es más fácil de establecer cuando la institución considera relevante la participación de un profesional archivero dentro de la organización antes de implementar un sistema de archivo. Es una forma de preparar el camino al archivo institucional, ya que permite disponer de antecedentes valiosos sobre procedencia y orden con que se presentan las series documentales y los cambios sufridos en el transcurso del tiempo. En concreto, la mejor manera de proyectar un archivo al interior de una organización es incorporar como metodología de trabajo inicial las técnicas de Gestión Documental, por un período no inferior a seis meses, tiempo durante el cual la actividad prioritaria del profesional será realizar un análisis documental acucioso.

Las siguientes son algunas recomendaciones y consejos para el profesional archivero que tiene por misión efectuar un análisis de la documentación en la fase de Gestión Documental. 
Es necesario primero examinar la legislación por la que se creó la organización y su estructura y cómo se han asignado sus funciones. Esto dará una idea básica del personal, organigrama, estatutos, normativas, reglamentos, etc.

Luego se recomienda la lectura de la documentación formal que la organización edita si esta existe, como memorias anuales, informes de gestión y desarrollo, manuales de uso interno, etc.

También es conveniente conocer la relación corporativa con otros organismos o empresas y grados de dependencia, ya que el fondo del archivo también lo integran documentos que afectan directamente las actividades de la organización y las acciones que las personas emprenden en determinados momentos. En este forma, las series documentales externas pasan a vincularse con la información producida internamente.

Es primordial el análisis de la documentación relativa a las funciones, procesos y circuitos de trabajo, ello ayuda a configurar y modelar la clase de tipologías documentales que utiliza la organización.

Importante es también la etapa de entrevista con el personal directivo a cargo de las funciones de dirección, gerencia, recursos humanos, administración, planificación, relaciones públicas, de estudios, etc. Por este medio se obtiene un cuadro completo de la organización. También es recomendable entrevistar a los funcionarios o empleados en las líneas de trabajo, para seguir junto a ellos los pasos de su desempeño y la información evacuada producto de su labor.

No me gustaría dejar pasar el tema de tecnología de la información (TI) haciendo mención de algunos aspectos que tiene que ver con la conservación y utilización de los archivos electrónicos. La literatura especializada expone múltiples ejemplos de la forma en que por esta vía se ha logrado enriquecer la actividad de análisis de información documental que debe realizar el profesional archivero. La Tecnología de Información (TI) para administrar sus recursos se está imponiendo en instituciones de todo tipo, mientras que la labor del profesional archivero sigue siendo fundamentalmente el tratamiento de la documentación en su formato de papel. En algún momento, este profesional deberá tomar algunas decisiones en cuanto al manejo, conservación o procesamiento de los llamados archivos electrónicos de datos, por lo que no podrá permanecer ajeno a este tema.

En los párrafos siguientes se enuncia una guía sobre el manejo e incorporación de archivos electrónicos a los archivos tradicionales, basada en el Proyecto Merkna impulsado en la década de los 90 por el gobierno danés; además agregar otras sugerencias que considero necesarias.

1. Los archivos electrónicos deben ser entregados y convertidos a un formato independiente de su sistema original.

2. Mantener dos copias de seguridad, una en el depósito del archivo y la otra en el organismo que lo ha producido. 
3. Los formatos de la información pueden ser guardados en un formato legible como TIFF, TXT o con extensión ASCCII.

4. Los archivos electrónicos de texto deben ser enviados comprimidos en un programa de uso común.

5. La entrega de base de datos deberá ser enviada en formato de texto.

6. Junto con los archivos electrónicos debe entregarse la documentación técnica del sistema de software que administra y procesa la información, para habilitar los registros para su lectura y tratamiento en el archivo.

7. El tiempo prudente de transferencia será de 5 a 10 años, o lo antes posible, ya que puede ocurrir que se vea amenazada la integridad en el uso del hardware y software.

8. Deberán realizarse inspecciones periódicas de los archivos electrónicos para asegurar que los registros se puedan leer y procesar.

9. Copiar o actualizar los registros en nuevos soportes, emigrando los datos en intervalos de10 años o tantas veces como sea necesario para conservar su integridad.

10. Designación de soportes en CD ROM o CD R, como medios principales de almacenamiento.

11. La plataforma de Internet para la consulta y acceso a los archivos electrónicos es una alternativa, siempre que se adopten las sugerencias anteriores y se implementen las interfaces de acceso y los programas de seguridad para servicios externos.

12. Es necesario mantenerse al tanto del avance en tecnología de información, para evaluar la migración de los datos, ya que si se conservan por mucho tiempo, la tecnología podría estar en desuso.

13. La durabilidad del software y del hardware son claves, pues es donde corren los archivos electrónicos; es imprescindible mantener la portabilidad de los archivos electrónicos en el tiempo.

\section{A ) Representación cartográfica de información documental como una guía de análisis para el trabajo archivístico.}

Después de realizar el análisis de los procesos relevantes de la organización y el análisis de la información documental que emana de la organización, recién estaremos en condiciones de hacer un levantamiento cartográfico para unir y visualizar los procesos con la salida de información documental concreta o la que se espera como predecible. 
La figura al costado refleja un esquema simple que permite visualizar una metodología que muestre cómo se va modelando la información por medio del desarrollo de una actividades de trabajo. De esta forma es posible ir haciendo un recorrido del proceso para saber en qué fases se producen los imput y output parciales o definitivos de información documental. El modelo permite también, identificar las tipologías documentales, su contenido, así como su frecuencia de generación sistemática o eventual.

$\mathrm{Si}$ bien lo anterior analiza el subproducto documental o elemento marginal que es el documento que emanado en un proceso de trabajo, el objetivo no es sólo verificar las salidas documentales o de información, sino que conjuntamente reconocer el producto o servicio que arroja dicho proceso, para entender con mayor propiedad la documentación generada, y que en definitiva afecta a un empleado en sus funciones o el curso de acción de un trámite administrativo. Esto significa que el profesional archivero al momento de analizar los procesos debe tener presente la suma de estos tres elementos proceso + producto/servicio + información documental, determinando sus grados de relevancia en la organización.

\section{3 - Selección y valoración}

Esta fase, junto al análisis de información documental, es una de las actividades archivística que requiere mayor cuidado en cualquier etapa del desarrollo de un archivo institucional, ya sea en una primera etapa de aplicación del trabajo de Gestión Documental o en los ciclos de vida que experimenta la documentación en los depósitos del sistema de archivo conforme fluye hacia un archivo central, intermedio o histórico.

El propósito de aplicar inicialmente un método de selección y valoración es conservar la documentación que representa un valor primario en curso, que se utiliza habitualmente o que potencialmente es apta para ser usada en el trabajo futuro. Por este motivo, en los archivos de oficina que es el lugar natural donde se va produciendo la documentación, aún no se puede hacer un descarte definitivo, se recomienda hacer una preselección y prevaloración. La recomendación a este respecto es mantener los archivos de oficina organizados, cuidando de no mezclar documentación o de adjuntar a la producción interna información irrelevante o con escasa vinculación al quehacer institucional o a la 
producción propia del departamento. Por tanto la implementación de una norma y un procedimiento ayudarán a ir separando en forma de selección natural lo que no debe juntarse con los documentos que emanan del propio archivo de oficina. Lo anterior no significa deshacerse inmediatamente de lo irrelevante o de información externa, ya que en este nivel estamos recién en el valor primario y todavía hay un uso y relación de los datos que contienen los documentos.

Distinto es si ya se encuentra en funcionamiento un sistema de archivo donde la selección y valoración se realiza de acuerdo a un programa definido, que permite establecer los niveles de selección y valoración ya sea directamente en las unidades de trabajo o en el depósito de almacenamiento intermedios dispuestos parta ello.

La primera acción en los lugares de generación de información documental debe estar determinada por un asesoramiento y una orientación y capacitación a los encargados de mantener los archivos de oficina.

\section{4 - Desarrollo de mecanismos de control}

El control aplicado a los procesos productivos de una empresa, a la gestión de un negocio, al cumplimiento de metas y objetivos, se ha transformado en un elemento esencial en actividades consideradas críticas o primordiales. Por una parte ayuda a desarrollar indicadores, e identificar estándares que aseguren un adecuado equilibrio del negocio y el cumplimiento de los objetivos; por otra parte, permite medir a través de sus indicadores el grado de desempeño de las personas y ayudar así a corregir las desviaciones que se puedan estar produciendo.

Dentro del concepto de control, hay algunas ideas que el profesional archivero debe considerar para identificar y desarrollar sus mecanismos de control en la fase de Gestión

\section{Documental.}

Control sobre el desarrollo de las tipologías documentales. Como ya se mencionó, toda organización desarrolla canales formales para la comunicación, para tramitar un asunto o solicitar el desarrollo de una tarea en particular (Por ejemplo, memorándums, oficios, circulares, notas internas, informes de productividad, de gestión, de finanzas, balances anuales, auditorias, etc.). Lo que se sugiere es evitar que se creen arbitrariamente nuevas tipologías documentales no reconocidas como dispositivos oficiales y formales por la organización.

Suele ocurrir que cuando se llenan cargos en nuevas divisiones o áreas de trabajo, la explicación a los nuevos empleados no aborda el manejo documental inherente a sus funciones, tema que muchas veces se descubre en el transcurso del trabajo cuando hay que tramitar los asuntos internos y externos en la organización. Una buena idea consiste en que el profesional archivero disponga de un inventario de todos las tipologías documentales que utiliza la institución, disponible para ejecutivos y empleados. 
El siguiente ejemplo que se muestra a continuación, responde a un modelo de mecanismos de control usados normalmente para realizar la transferencia de series documentales en un sistema de archivo.

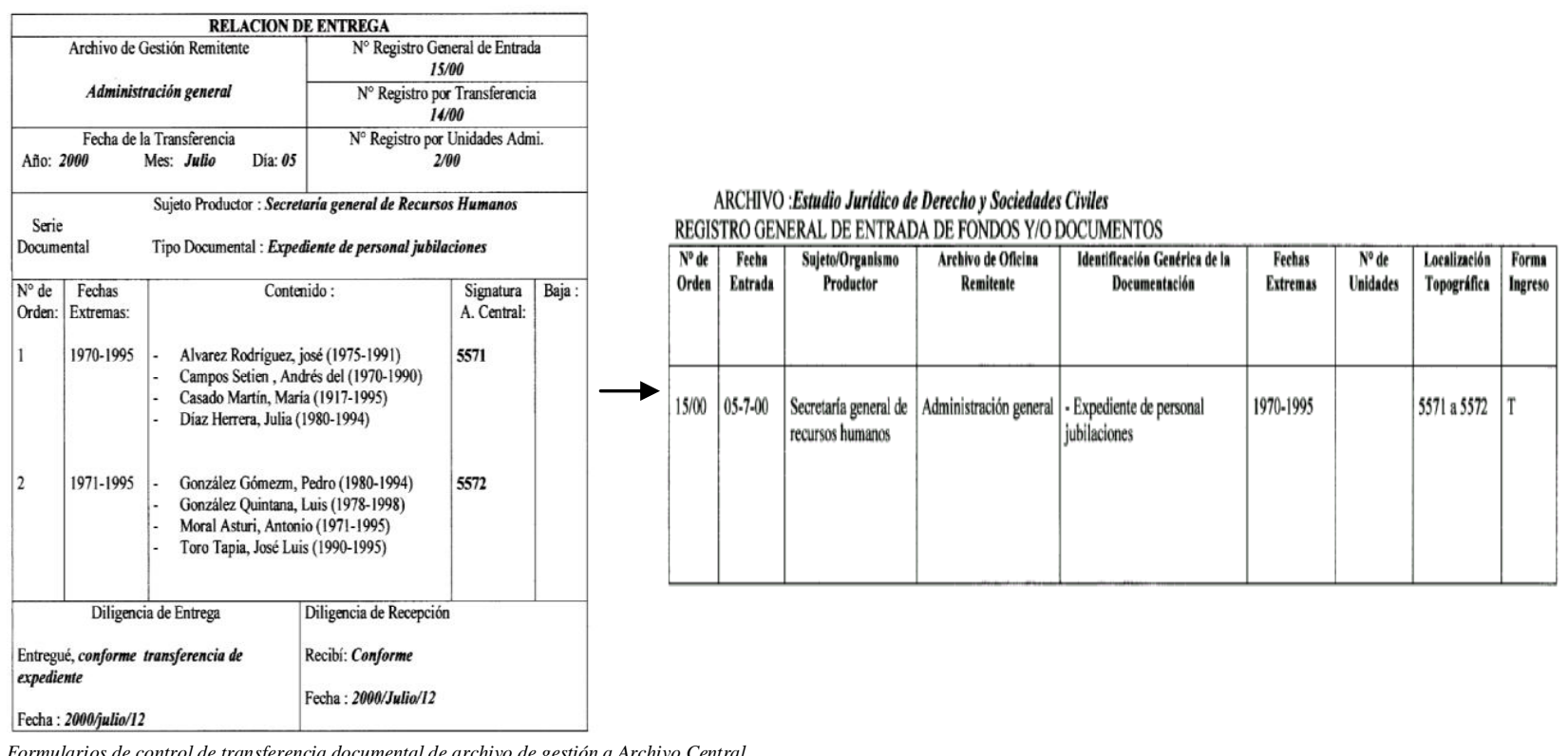

Se puede observar el traspaso de la documentación de un archivo de gestión a un archivo central, registradas las hojas de ruta con las que deben trasferirse la documentación y la descripción de sus series. Aún cuando no se disponga de un sistema de archivo que norme en el tema, siempre es conveniente crear los dispositivos de control para derivar la documentación de los lugares de trabajo a los depósitos provisorios. Lo valioso de este proceso es que en el futuro se puede disponer de una importante información de gestión para reconstruir la historia de la organización a través de su documentación, al mismo tiempo se mantiene el principio de procedencia y el orden natural de los documentos a la hora de crear el archivo definitivo.

Otro elemento que debe preverse es el control sobre la duplicidad de la información. Es frecuente en el trabajo administrativo el envío de documentos a un destinatario en particular, y al mismo tiempo reenviar copias innecesarias a otras autoridades o jefaturas, como una forma de respaldar el trabajo realizado, sin que se justifique dicho envío. Es suficiente que los documentos sean reconocidos y entendidos por quienes corresponde, ya que el flujo de la información debe estar sustentada por la cadena de mando y no por el supuesto que dicha información es relevante también para otros no competentes. Otro efecto que provoca esta situación es aumentar innecesariamente la documentación y con ellos el trabajo del profesional archivero, ya que un mismo documento se ha duplicado o triplicado en más de un lugar en la organización.

Con el uso de la tecnología de la información (TI) es común el uso del correo electrónico (e-mail) para el envío de documentos que tienen el carácter de oficial. Se piensa que la rapidez en el envío de información por esta vía asegura que las personas puedan estar al tanto de lo que se requiere, así como la ejecución de algunas tareas, pero al respecto se presenta un problema con la documentación, es que necesariamente necesitan ser firmadas o visada para y luego puedan ser incorporados al archivo de oficina. Una recomendación a este respecto es usar la tecnología como una plataforma para informar y economizar tiempo, pero remitir con posterioridad el documento 
firmado al departamento o unidad de trabajo, así el archivo dispondrá de documentos que puedan ser usados como antecedentes de carácter legal y como sustento al tramite administrativo.

El control de la información en papel que suele almacenarse en disquete es otro aspecto importante, que requiere de políticas y procedimientos adecuados. Si la institución ha establecido manejar cierta documentación en papel, no debe cambiarse de estatus; pueden mantenerse provisoriamente dispositivos electrónicos de respaldo como disquete, y ser usados eventualmente cuando se proceda al inventario anual y cierre del archivo de oficina, o cuando se haya perdido o dañado un documento. En este último caso deberá ser reproducido del respaldo para integrarlo a la secuencia de su serie documental en el archivo de oficina, previa firma de quien proceda.

Otro mecanismo de control consiste en inspecciones del profesional archivero en la organización, para verificar que no se estén produciendo por parte de los empleados o directivos tipologías documentales que no se ajustan a las usadas normalmente. A este respecto hay que ser muy riguroso, ya que la eficiencia mal entendida lleva a suponer que la rapidez en hacer el trabajo y comunicar diligentemente la información, es más importante que el conducto administrativo y comunicacional diseñado por la institución, permitiendo que cada uno de ellos diseñe sus propios dispositivos de comunicación y desarrollo de tareas no ajustada a las normativas. Puede parecer que esto no tiene mayor importancia, pero a la hora de hacer el análisis documental puede producir equívocos. Esto no significa que el profesional archivero reprima estas prácticas, al contrario lo que procede es estudiar la forma de mejorar los dispositivos proponiendo innovaciones a las formas tradicionales por otras más eficientes, de acuerdo con los cambios en el trabajo.

Estos mecanismos de control no pretenden burocratizar el funcionamiento del trabajo y la generación de documentos ni colocarle cortafuegos a las personas, obligándolas a proceder de determinada forma. Lo que se espera con estas herramientas en el contexto de la Gestión Documental es seguir un orden establecido por la organización, detectar y corregir posibles errores y minimizar el caos en la documentación que crece exponencialmente en la medida que la organización crece.

\section{Conclusión}

Las técnicas de Gestión Documental insertas recientemente en la archivística tuvieron su principal escenario en Quebec en 1992. En ese encuentro se analizó una nueva forma de abordar el trabajo documental, pero sin desvincularlo todavía del concepto de la archivística tradicional donde el profesional archivero es aún un interventor de documentos no preocupado de establecer una relación documental con el desarrollo de la organización. (Ramos Jiménez1999) afirma que la archivística integrada "une en una misma ciencia o técnica todas las clases de archivos, ya que es una necesidad fundamental en la actualidad abarcar totalmente el tratamiento de la documentación desde su inicio u origen donde se genera en un circuito de trabajo, actividad administrativa, hasta su conservación definitiva pasando las 3 edades de la documentación para los tres tipos de archivos, el de gestión, el general e histórico, con los períodos de valoración y selección que se aplica en cada fase critica de su vida.” 
La pregunta que cabe hacerse en el marco de la Gestión Documental en un contexto de integralidad, ¿está la acción del profesional archivero vinculado realmente a la documentación y la organización en su conjunto,? relacionando funciones, procedimientos de trabajo, personas, logros y defectos de la organización, o sólo está presente en la intervención documental hasta donde la organización le permita llegar, sin influir mayormente en su desarrollo institucional.

Mirando al futuro, conviene citar a (E. Yake2000) quien sostiene que "a los profesionales de la Gestión Documental rara vez se les asocia al concepto de Gestión del Conocimiento (Knowledge Management); en este mundo de trabajo de conocimiento y organizaciones creadoras de experiencias los Directores de Archivos no pueden ser percibidos únicamente como proveedores de servicio y conservadores de documentos". Los profesionales archiveros deben ser considerados agentes de intermediación de conocimiento; los archivos son reservas de valor presente y futuro institucional y es la aplicación de la Gestión Documental lo que le da ese valor, desarrollando una actividad archivística con más elementos de análisis y decisión, para lograr así convertirse en soportes sustantivos para la Gestión del Conocimiento en la organización.

Hoy en día, cuando la información se dispersa rápidamente, no se puede pensar que las técnicas desarrolladas por la Gestión Documental se manejen en un frente distinto a la teoría archivística; las metodologías tradicionales deben ser renovadas y aplicadas tanto al recurso documental como al entorno organizacional y no sólo a la intervención y tratamiento de documentos. Es un hecho que el futuro de la gestión de los documentos no está en los propios documentos sino en el destino del archivo para dar un mayor valor a la organización. Es necesario imaginar una nueva perspectiva de la Gestión Documental; se debe cambiar el concepto tradicional de intervenir la documentación, por la idea de relación documental con la organización.

Los profesionales archiveros deben ser capaces de identificar y reconocer la complejidad de las organizaciones y de su entorno; el error es considerar que el límite de su accionar está dado por la intervención de los documentos dentro del archivo, anulando así la influencia que pueden ejercer los archivos en la "ecología corporativa de la organización". Los archivos deben mirarse insertos e interrelacionados en el ambiente ecológico organizacional, es decir, un conjunto constituido por personas, actividades, prácticas de trabajo, tecnología, productos y servicios, información, valor, conocimiento, etc.

Entonces, el nuevo paradigma está en el papel del archivo como Knowledge Management (gestión de conocimiento), que analiza el cambio de la organización a través de tradicionales y nuevas formas documentales, vinculadas a nuevas metodologías, procedimientos y tecnología. 


\section{BIBLIOGRAFIA}

AKOTIA, Pino (1994). The National Archives of Ghana: new responsibilities and challenges. Records Management Quarterly, 28(4): 33-37.

Conferencia de Archiveros de Universidades Españolas CAU. Universidad de Granada, 1995. cau/CAU10.HTM>

DAVENPORT, Thomas (1999). La gestión del conocimiento no es más que una eficaz administración de la información. Management en Administración de la Información, (6):1-5.

DRUCKER, Peter F(1999). Cuál es la información que necesitan los ejecutivos. Management en Administración de la Información, (12):1-4.

FUENZALIDA Riveros, Eduardo (1999). Elementos de administración estratégica, Santiago. Departamento de Sistemas de Información y Auditoria. Facultad de Ciencias Económicas y Administrativas. Universidad de Chile.

HARRY, Joe (2000). Records management system recovers big dollars. THE Journal, 28(4):7-16.

JIMÉNEZ Bermejo, Patricio (1996). Control de gestión. Santiago, Jurídica Conosur.

KLIKWOOD, Clive (2994). Records management in the public sector and the archival challenges poses by electronic record. South Africa Archives Journal, 36 : 7-4.

LODOLINI, Elio (1993). Archivística : principios y problemas. Madrid, Asociación Española de Archiveros, Bibliotecarios, Museólogos y Documentalistas.

LORINO, Philippe (1995). El control de gestión estratégica: la gestión por actividad. Santafé de Bogotá, Alfaguara.

MNJAMA, Nathan M. (1996). National archives and the challenges of managing the entire life cycle on records. South African Archives Journal, 38:24-33.

RAMOS Jiménez, Joaquín (1999). Curso práctico de archivística, Santander, Centro Técnico de Estudios, 1999.

RUIZ Rodríguez, Antonio Ángel (Edit.) (1995). Manual de archivística. Madrid, Síntesis.

YAKEL, Elizabeth (2000). Knowledge management: the archivist's and record manager's perspective. Information Management Journal, 34(3): 24-30. 